\title{
Male infertility due to sulphasalazine
}

\author{
R. TOBIAS* \\ M.B., Ch.B., M.R.C.P. \\ T. COETZEe $\dagger$ \\ M.D., M.R.C.P., Ch.M., F.R.C.S., D.P.H., D.I.H.
}

${ }^{*}$ Gastrointestinal Clinic, Groote Schuur Hospital, Cape Town; †Department of Obstetrics and Gynaecolog and $\ddagger$ Department of Medicine, Cape Town Medical School, Cape Town, South Africa

\section{Summary}

A male patient presented with infertility and was found to have severe oligospermia and a low serum testosterone. Three months after stopping sulphasalazine, both abnormalities returned to normal and his wife subsequently became pregnant.

\section{Introduction}

Sulphasalazine-induced oligospermia has recently been recognized (Toth, 1979; Levi et al., 1979; Grieve, 1979), but concomitant low serum testosterone concentration has not been documented. A case of reversible oligospermia and low serum testosterone due to sulphasalazine is reported.

\section{Case report}

A 39-year-old white male with a 15-year history of ulcerative colitis involving the left colon was admitted to hospital on 2 July 1980 with acute symptoms. He had been on sulphasalazine $1 \mathrm{~g}$ twice/day for at least one year before admission. His past history included hepatitis, malaria and nonspecific urethritis. The latter resulted in an urethral stricture, requiring intermittent dilatations, the last of which had been performed 5 years previously. Physical examination was unremarkable apart from the sigmoidoscopic findings of grade 3-4 colitis. His symptoms remitted on prednisone $60 \mathrm{mg}$ daily, prednisolone enemas twice/day and increasing the sulphasalazine to $1 \mathrm{~g}$ thrice/day. He was discharged on the 11 July on that dose of sulphasalazine and prednisone $45 \mathrm{mg}$ daily, reducing to $30 \mathrm{mg}$ over the next month.

On 15 August a semen analysis was performed because of his wife's infertility after 18 months of marriage. This showed the presence of 'occasional dead sperms' only. Serum hormone levels were (normal ranges in brackets): luteinizing hormone (LH)-8.2 mi.u./ml (5-15 mi.u./ml); follicle stimu- lating hormone (FSH)-16.7 mi.u./ml (5-15 m.i.ü $\mathrm{ml})$ and testosterone- $5.4 \mathrm{nmol} / 1 \mathrm{l}(10-55 \mathrm{nmol} / 1)$ 여 The sulphasalazine was immediately stopped an $\$$ the prednisone reduced to $15 \mathrm{mg}$ daily over the following month.

On 19 September the hormone levels were옹 LH-4.7 mi.u./ml; FSH-11.3 mi.u./ml and testo sterone-7.9 nmol/l. He was on $15 \mathrm{mg}$ of pred₹ nisone daily. During the following month he hadarec exacerbation of symptoms and the dose of predes nisone was increased to $80 \mathrm{mg}$ daily, but sulphasalazine was withheld.

On 28 November he was symptom-free and taking prednisone $10 \mathrm{mg}$ daily. Serum testosterone wa\& normal $-12.4 \mathrm{nmol} / \mathrm{l}$ and the semen analysis was compatible with fertility at $138.5 \times 10^{6} / \mathrm{ml}$. On the 21 February 1981 his wife's pregnancy wa confirmed.

\section{Discussion}

Sulphasalazine was first used in clinical practice in 1942 (Svartz, 1942). It is composed of sulpha?. pyridine and 5-aminosalicylate (5-ASA) linke through an azo bond (salicylazosulphapyridine) About $15 \%$ is absorbed as the parent drug and the rest splits into its component agents. It is used for maintenance therapy in inflammatory bowel disease and the therapeutic effect is exerted through the 5 -ASA of which $80 \%$ is excreted through the bowel The association with infertility was recognized in 1975 (Grieve, 1979) but the first reports of reversible oligospermia with resultant pregnancy were onlyo published in 1979 (Toth, 1979; Levi et al., 1979). స

The cause of oligospermia due to sulphasalazine therapy is not known, but several theories areo postulated. Sulphasalazine is a competitive inhibitoro of the enzyme system for folic acid transport across? the bowel wall (Selhub, Jeelani Dhar and Rosenberg, 0 1978) and may suppress the rapid turnover of cells 
which occur in spermatogenesis. Prostaglandin concentrations $\left(\mathrm{PgE}_{2}\right)$ are lower in seminal fluid of subfertile men and raised concentrations can increase sperm motility in vitro (Bygdeman, 1969). Seventyseven per cent. to $98 \%$ inhibition of prostaglandin turnover occurs in men on therapeutic doses of salicylates and larger doses of aspirin reduce seminal prostaglandin concentration by $50 \%$ after $2-6$ days. Two to $3 \mathrm{~g}$ of sulphasalazine would yield only onethird of the therapeutic dose of aspirin, but this may cause partial suppression of prostaglandin synthesis (Toth, 1979).

In view of this patient's reversible low serum testosterone, a third possible mechanism is suggested. This hormone is secreted from the Leydig cells and is essential for the development of male accessory sex organs, prostate, seminal vesicles and semen production. It acts directly on the seminiferous tubules and the amount of testosterone 'bathing' the tubules is important for spermatogenesis (Pepperell, Hudson and Wood, 1980). Testosterone synthesis and spermatogenesis are controlled by the hypothalamic pituitary axis. LH acts on Leydig cells to induce testosterone synthesis and FSH initiates spermatogenesis. In this patient, both FSH and $\mathrm{LH}$ levels were normal and the sulphasalazine appears to have had a direct suppressive effect on the Leydig cells. Several drugs can block one or more enzymes necessary for the synthesis of testosterone from cholesterol, resulting in impaired spermatogenesis (Amelar, Dubin and Walsh, 1977). Although a testicular biopsy was not performed in the present patient, this may be the mechanism by which the sulphasalazine acted, rather than by structural damage to the cells. The rapid reversibility tends to support this theory.

Apart from a reduced count, the spermatozoa of men on sulphasalazine have shown reduced motility and morphological abnormalities of the head, midpiece and tail segments. A characteristic 'megalo'-cell type has been reported in 3-8\% of spermatozoa, but this may only represent an increased osmotic fragility of the head (Toth, 1979). Toovey, Levi and Hendry (1980) reported on the semen analysis of 18 patients with inflammatory bowel disease who were on long-term sulphasalazine therapy. Eight had complained of infertility. Of the specimens examined, sperm density was below normal in 15 out of 17; motility was reduced in all 18 patients and morphology was abnormal in 10 out of 16 . There were no significant differences in these 3 parameters whether patients complained of infertility or not. Thus, sulphasalazine appears to have a significant effect on spermatogenesis and fertility, but this does not become apparent unless the patient complains. The changes are usually reversible within 3 months of stopping the drug and conception usually follows.

Prednisolone has been shown to inhibit spermatogenesis if administered at a dosage of $30 \mathrm{mg}$ daily for at least one month, but these changes may not revert to normal even at 6 months (Mancini et al., 1966). In view of the present patient's relatively rapid recovery and the fact that he was on prednisone $80 \mathrm{mg}$ daily within one month before his second semen analysis, it seems unlikely that this drug played a part in his oligospermia. Levi et al. (1979) described a patient whose oligospermia returned to normal despite his remaining on $25 \mathrm{mg}$ prednisone and prednisolone enemas daily.

The use of sulphasalazine as a male contraceptive has been considered. Whatever its mode of action, it does not appear to cause serious damage as it is readily reversible. However, other side effects of the parent molecule preclude its use and research is being aimed at isolating the active principle without the hazards of the sulphur moiety (Levi, Toovey and Hudson, 1981). When prescribing this drug to young male patients, doctors should be alert to the possibility of iatrogenic infertility.

\section{Acknowledgments}

We thank Dr H. R. Sanders, Principal Medical Superintendent at Groote Schuur Hospital for permission to publish, and Mrs M. Bloch for typing the manuscript.

\section{References}

Amelar, R.D., Dubin, L. \& Walsh, P.C. (1977) Malc Infertility p. 46. W. B. Saunders Company, Philadelphia.

Bygdeman, M. (1969) Prostaglandins in human seminal fluid and their correlation to fertility. International Journal of Fertility, 14, 228.

GrIEve, J. (1979) Male infertility due to sulphasalazine. Lancet, ii, 464.

Levi, A.J., Fisher, A.M., Hughes, L. \& Hendry, W.F. (1979) Male infertility due to sulphasalazine. Lancet, ii, 276.

Levi, A.J., Toovey, S. \& Hudson, E. (1981) Male infertility due to sulphasalazine. Gastroenterology, 80, 1208.

Mancini, R.E., Lavieri, J.C., Muller, F., Andrada, J.A. \& SARACENI, D.J. (1966) Effect of prednisolone upon normal and pathologic human spermatogenesis. Fertility and Sterility, 17, 500 .

Pepperell, R.J., Hudson, B. \& Wood, C. (1980) The Infertile Couple, p. 76. Churchill Livingstone, Edinburgh.

Selhub, J., Jeelani Dhar, G. \& RosenberG, I.H. (1978) Inhibition of folate enzymes by sulfasalazine. Journal of Clinical Investigation, 61, 221.

Svartz, N. (1942) Salazopyrine, a new sulfonilamide preparation. Acta medica scandinavica, 110, 577.

Toovey, S., Levi, A.J. \& Hendry, W.F. (1980) Sulphasalazine and male infertility. Gut, 21, A911.

Tотн, A. (1979) Reversible toxic effect of salicylazosulfapyridine on semen quality. Fertility and Sterility, 31, 538. 